\title{
ASSIMETRIAS ENTRE OS COMPETIDORES NOS LEILÕES DA ANP
}

\author{
Eric Universo Rodrigues Brasil * \\ Fernando Antonio Slaibe Postali ${ }^{\dagger}$
}

\begin{abstract}
Resumo
Este artigo investiga assimetrias entre os concorrentes dos leilões para exploração de petróleo no Brasil, através da comparação estatística das distribuições dos lances, estimadas por procedimentos não paramétricos. Uma análise exploratória dos lances empreendidos, contendo diversas combinações de jogadores, corroborou a expectativa da presença de assimetrias em favor da Petrobras e da OGX. Comparamos as distribuições e testamos diferenças a partir do teste de Kolmogorov-Smirnov. Os resultados reforçam a hipótese de assimetrias, mas há evidências estilizadas compatíveis com a presença de assimetrias de natureza informacional e também de custos.
\end{abstract}

Palavras-chave: Leilões; Indústria do petróleo; Regulação.

\begin{abstract}
This article investigates asymmetries among bidders in the bidding for oil in Brazil, by comparing statistically the distributions of bids. Distributions are estimated by nonparametric procedures. An exploratory analysis of the bids, containing several combinations of players, confirmed the expectation that there are asymmetries in favor of Petrobras and OGX. We compare the distributions and test differences using the KolmogorovSmirnov test. The results support the hypothesis of asymmetries, but there is stylized evidence consistent with both informational and cost asymmetries.
\end{abstract}

Keywords: Auctions; Oil industry; Regulation.

JEL classification: D44, L71

\footnotetext{
* Tendências Consultoria e IPE-USP. E-mail: euniverso@tendencias.com.br

† Departamento de Economia, FEA-USP e bolsista CNPq. E-mail: postali@usp.br
} 


\section{Introdução}

Em 1997 entrou em vigor no Brasil a lei que ficou conhecida como Lei do Petróleo ( $\mathrm{n}^{\circ}$ 9.478/97), instituindo um novo marco regulatório para o setor. Em essência, o ambiente institucional que passou a vigorar representou a quebra do monopólio estatal nas atividades de exploração e produção (E\&P) de petróleo e gás natural no país, até então operadas pela Petrobras. Apesar de não revogar a propriedade exclusiva da União sobre tais recursos (conforme manda a Constituição), a nova lei autorizou a concessão dessas atividades à iniciativa privada.

Com a nova lei, a União passou a conceder direitos de E\&P a partir de leilões de licitação gerenciados pela Agência Nacional do Petróleo - ANP. O processo foi estruturado com base em leilões fechados de primeiro preço, ${ }^{1}$ no qual cada participante submete simultaneamente uma proposta por escrito em envelope lacrado, em uma sessão pública. O vencedor é determinado a partir de um índice que pondera o lance oferecido (Bônus de Assinatura), o programa exploratório e o compromisso de utilização de mão de obra local. De 1999 a 2008, foram realizadas dez rodadas de licitação, com cerca de três mil blocos de área para exploração sendo oferecidos. ${ }^{2}$

Os lances e os resultados desses leilões constituem uma base de dados que pode revelar particularidades importantes do mercado brasileiro de prospecção de gás e petróleo, fornecendo subsídios para avaliações mais profundas a respeito dos sucessos e fracassos do modelo de licitação adotado. Tais estudos ganham ainda maior relevância diante do atual processo de revisão do marco regulatório do setor, após a descoberta das reservas do pré-sal em 2007.

Entre os temas importantes à análise da eficiência do arranjo institucional adotado com a Lei do Petróleo, inclui-se a estrutura competitiva vigente nas licitações. Na ausência de competidores assimétricos, um leilão cujos participantes dão um único lance simultaneamente será tão mais eficiente na alocação do ativo leiloado ${ }^{3}$ quanto mais homogêneas forem as condições competitivas vigentes entre os competidores. No entanto, na presença de assimetrias, pode ser desejável conceder vantagem ao tipo que tem mais disposição a pagar, mas a caracterização de uma competição com tipos heterogêneos não é tarefa trivial. Em linha com o argumento de Mattos (2008) a existência de assimetrias entre os competidores dos leilões da ANP é uma hipótese bastante razoável. Isso porque a Petrobras, além de ser uma concorrente do leilão controlada pelo próprio governo, foi durante quase cinquenta anos monopolista do setor, tendo a incumbência de prospectar todo o território brasileiro. Essas características geram questionamentos a respeito das licitações conduzidas pela ANP: será que a Petrobras gozou de vantagens sobre os demais participantes nesses leilões? Em caso afirmativo, qual teria sido a natureza dessa vantagem? Trata-se de uma vantagem informacional, conforme sugerido por Mattos (2008), tecnológica ou refere-se à sua condição de estatal? A análise combinada da teoria e dos dados pode contribuir para o esclarecimento destas

\footnotetext{
${ }^{1}$ Ver McAfee \& McMillan (1987).

${ }^{2}$ Após a realização das dez rodadas, os leilões foram suspensos de 2009 a 2012, à medida que o marco regulatório para o pré-sal vem sendo construído. Em maio de 2013, uma nova rodada foi realizada.

${ }^{3}$ A eficiência aqui citada refere-se não só a alocação do ativo para o agente com maior disposição a pagar e cobrando o maior valor possível, mas também ao agente com melhores condições de gerir o ativo leiloado, maximizando o ganho social obtido com a respectiva licitação.
} 
e outras questões referentes ao mercado brasileiro de exploração e produção de petróleo. Há uma extensa literatura teórica e empírica recente apontando que o estudo de leilões permite detectar assimetrias entre seus participantes (e.g. Athey \& Haile 2002, 2006, Bajari \& Hortacsu 2005, Campo et al. 2003, Hendricks et al. 2003)

O objetivo deste trabalho é investigar características estilizadas dos lances empreendidos nas dez rodadas de leilões de E\&P conduzidas pela ANP a fim de encontrar evidências de assimetrias entre os participantes, bem como oferecer algumas interpretações sobre sua natureza. Os resultados encontrados apresentam características que, conforme apontam Campo et al. (2003), são consistentes com a presença de assimetrias: a Petrobras tende a arrematar uma maioria significativa dos leilões, e os lances dos demais participantes são normalmente mais elevados quando a Petrobras está presente. Por outro lado, o coeficiente de variação dos lances dos demais jogadores tende a ser maior na ausência da Petrobras nos leilões. Adicionalmente, o caso brasileiro apresenta um experimento que pode ser informativo sobre a natureza das assimetrias entre os competidores: a entrada da empresa OGX que - após absorver uma parte importante dos quadros profissionais qualificados da Petrobras - liderou o desempenho na única rodada de leilões de que participou. Embora a evidência não seja conclusiva nesse estágio, os resultados são consistentes com a hipótese de que houve transferência de vantagem informacional da estatal para a OGX. De fato, a OGX absorveu apenas quadros profissionais, e não capital físico da Petrobras. Por fim, as distribuições dos lances da Petrobras/OGX e dos demais jogadores foram estimadas e comparadas estatisticamente a partir do teste de Kolmogorov-Smirnov, cujos resultados corroboram a presença de assimetrias nos lances. Todavia, não se pode também rejeitar a hipótese de que as assimetrias são provenientes de diferenças de condições de produção (custos) entre os competidores.

Este artigo se divide da seguinte forma: na seção a seguir, apresentamos algumas linhas gerais da teoria dos leilões e a existência de assimetria entre os participantes; na seção 3, relatamos alguns fatos estilizados que sugerem a presença de assimetrias entre competidores nas rodadas brasileiras de licitação de petróleo, com base nas predições gerais dos modelos de Porter (1995) e de Hendricks et al. (1994), cujos resultados principais são brevemente relatados na seção 4; as seções 5 e 6 trazem um sumário geral dos dados, além de algumas estatísticas gerais; a seção 7 apresenta o procedimento de estimação da distribuição dos lances e o teste de Kolmogorov Smirnov, assim como seus resultados. A última seção tece algumas considerações finais.

\section{Leilões de petróleo e assimetria entre participantes}

Uma vasta literatura teórica sobre leilões pode orientar os estudos empíricos sobre o tema. Usualmente, classificam-se os leilões segundo dois critérios: (i) definição dos preços que os vencedores pagam e (ii) maneira pela qual as propostas são realizadas. A respeito do primeiro critério, o leilão pode ser de primeiro-preço, em que o vencedor paga o valor de sua oferta, ou de segundopreço (Vickrey 1961), na qual o vencedor paga o valor do segundo maior lance oferecido. Em ambos os casos, o vencedor é aquele que oferecer a maior proposta. Com respeito ao segundo critério, o leilão pode ser aberto, no qual os lances são anunciados ao público, ou fechado, em que cada participante 
apresenta seu lance simultaneamente, sem ter conhecimento dos lances adversários. Dessa forma, estruturam-se as quatro formas básicas de leilão: i) leilão inglês ou ascendente; ii) leilão holandês ou descendente, iii) leilão fechado de primeiro preço e iv) leilão fechado de segundo preço.

Com relação à hipótese quanto à forma como o bem é avaliado pelos participantes, a literatura destaca duas modalidades de leilão: (i) leilão de valor privado, no qual os agentes, de forma independente ou correlacionada, atribuem um valor subjetivo e particular ao bem e (ii) leilão de valor comum, em que todos os competidores atribuem um mesmo valor ao ativo, embora este valor seja desconhecido dos participantes (Laffont \& Vuong 1996). Entre esses dois extremos, Milgrom \& Weber (1982) construíram um paradigma informacional geral, assumindo que os agentes formam seus valores de reserva a partir da observação de dois componentes, sendo um de observação geral (componente de valor comum) e outro dependente das particularidades do agente (componente de valor privado).

Os resultados obtidos em modelos com essas duas formas de avaliação são distintos. Myerson (1981) demonstrou que, em um ambiente simples de valor privado, nenhum dos quatro formatos de leilão acima mencionados tem vantagem sobre os demais, produzindo sempre o mesmo resultado. No entanto, conforme apontam Milgrom \& Weber (1982), o modelo de valor comum pode eliminar essa equivalência. Isso se deve ao fato de que, em um ambiente de valor comum, um competidor tem informações sobre o valor do objeto para os demais. Com isso, em leilões do tipo fechado, não há a possibilidade de essas informações serem transmitidas ao longo da realização dos leilões, como ocorreria com um leilão aberto.

A utilização de modelos de valor comum em concessão de direitos de exploração de recursos minerais aparece na literatura já nos anos 1960, tendo entre seus pioneiros Wilson (1969) e Ortega-Reichert (1967). Uma importante característica dos leilões para concessão de áreas de exploração de petróleo é a tentativa das companhias de estimar um valor comum para o objeto leiloado. As reservas de petróleo em uma dada área não são perfeitamente conhecidas, e o valor dessas reservas, em grande medida, independe do concorrente que as explore. ${ }^{4}$ Por natureza, trata-se de um leilão de valor comum desconhecido ex-ante. Nessa situação, a informação imperfeita pode resultar em uma ineficiência conhecida como "maldição do vencedor". ${ }^{5}$ (Kagel \& Levin 1986): admitindo-se que as estimativas acerca do valor do objeto sejam não viesadas, a existência de estimativas acima da média resulta na superestimação do valor verdadeiro do objeto pelo lance vencedor. Dessa forma, o participante que adquire o objeto por ter oferecido o maior lance tenderá a pagar um preço acima do seu valor verdadeiro.

De acordo com McAfee \& McMillan (1987), os leilões de primeiro preço selado (modelo utilizado pela ANP) são mais suscetíveis aos problemas da maldição, pois como os lances são fechados, cada participante faz sua oferta sem saber o lance dos demais, sendo inviável a revisão de expectativas para a

\footnotetext{
${ }^{4}$ Por vezes, esse valor não é exatamente igual entre os concorrentes por conta de diferenças nos custos de exploração e produção.

${ }^{5}$ Segundo, Roth \& Kagel (1995) a ocorrência da maldição do vencedor foi inicialmente constatada empiricamente por Capen et al. (1971) Eles observaram que as companhias detentoras de concessão de áreas de exploração de petróleo a partir de leilões não conseguiam obter todo o volume de óleo que inicialmente esperavam extrair, pois os vencedores possuíam a projeção de extração mais alta, resultando em lances mais altos do que o valor efetivo do bloco concedido.
} 
incorporação de informações a respeito das outras ofertas (Milgrom \& Weber 1982). Thaler \& Tucker (1995) mostram que no caso dos leilões de exploração de petróleo no Golfo do México, entre 1954 e 1969, do total de arrendamentos dos campos petrolíferos, $62 \%$ eram improdutivos, $16 \%$ produziam, mas sem lucro e apenas $22 \%$ apresentavam lucros relevantes, interpretando esses resultados como evidências da maldição do vencedor. Hendricks et al. (2003) também analisam dados de leilões de petróleo e gás (ocorridos nos EUA entre as décadas de 50 e 70), sendo que seus principais resultados também sugerem a presença da maldição do vencedor, principalmente na forma de receio dos participantes quanto a esse fenômeno. Note-se que, em um mundo com agentes racionais, antecipa-se a tendência do vencedor a superestimar o valor de um objeto. O receio da maldição do vencedor faz com que os participantes ofereçam lances mais baixos, resultando em perda esperada igual a zero. Uma consequência natural desses cenários é que os agentes mais bem informados a respeito do verdadeiro valor do ativo tendem a aplicar um "desconto" menor em seus lances, em função do menor receio da maldição do vencedor. Nesse sentido, a vantagem informacional pode resultar em maior probabilidade de ganho do leilão.

Os leilões representam um mecanismo de precificação no qual um ofertante busca extrair a totalidade do preço de reserva de um demandante (McAfee \& McMillan 1987). Dessa forma, a assimetria de informação é um ingrediente intrínseco aos leilões, tendo em vista que os preços de reserva são informações privadas dos participantes, fora do conhecimento perfeito do leiloeiro. Quando há assimetrias entre os candidatos a adquirente do ativo leiloado, sejam elas informacionais ou de outra natureza, o resultado do leilão tende a divergir daquele que sobressairia num cenário de simetria entre os competidores, o que pode minar a eficiência deste mecanismo.

No que concerne a leilões de petróleo e gás, Hendricks et al. (1994) examinaram como as assimetrias de informação entre os jogadores em um leilão afetam seus comportamentos estratégicos. A análise foi realizada a partir da existência de um comprador com informações privadas superiores a todos os outros participantes, os quais só têm acesso a informações públicas. Os autores concluem que o comportamento de equilíbrio, sob esta estrutura de informação, leva os participantes com pouca informação a ofertarem frequentemente menos que o participante com informação privada. Dessa forma, a distribuição dos lances do licitante informado domina a distribuição dos lances de seus concorrentes. No mesmo arcabouço, Porter (1995) analisou leilões de concessão de áreas offshore pelos EUA a partir de 1954, concluindo que os resultados aderiram bem ao modelo sugerido anteriormente.

Ainda sobre leilões de concessão de áreas de exploração de petróleo nos EUA, ocorridos entre 1972 e 1979, Campo et al. (2003) implementaram estimativas não paramétricas da distribuição dos valores privados à luz de um modelo estrutural que assume assimetria tecnológica entre as empresas. Os resultados obtidos indicaram que a renda de informação média foi de 65,1\%, sendo $65,5 \%$ para lances de empresas pertencentes ao grupo dos competidores favorecidos pela assimetria e $64,6 \%$ para lances de empresas do grupo dos desfavorecidos. 


\section{Indícios de assimetria nos leilões para exploração de petróleo no Brasil}

A caracterização de uma situação de assimetria de informações em um mercado de leilões é uma tarefa complexa. Em primeiro lugar, mesmo observando lances com diferentes distribuições, a natureza dessa assimetria não é facilmente identificada, pois pode estar ligada tanto a aspectos informacionais quanto tecnológicos. Além disso, a oferta de lances é uma decisão em dois estágios: no primeiro estágio, o agente toma a decisão de entrar ou não no leilão (margem extensiva); no segundo estágio, decide-se quanto ofertar pelo bem, dada a entrada (margem intensiva). A presença de um grande competidor, nesse sentido, pode afetar a decisão de tomar parte em um leilão pelos demais agentes, de forma que o perfil da assimetria é endógeno à participação esperada nas rodadas de licitação.

A fim de ilustrar este ponto, a Tabela 1 apresenta alguns dados relativos à margem extensiva. As empresas interessadas em blocos leiloados devem manifestar interesse a partir do pagamento de uma taxa para a obtenção de dados geológicos. A Agência Nacional do Petróleo, a partir da análise da capacidade operacional e financeira das candidatas, habilita os participantes, configurando os entrantes potenciais no leilão. A decisão de participar do certame é dada pela oferta de lances em cada um dos blocos disponibilizados. Como se pode observar pela Tabela 1, na primeira rodada, realizada em 1999, apenas $37 \%$ das empresas habilitadas ofertaram lances (14 em 38), ao passo que a média se situa em torno de $62 \%$ (235 em 377). Uma interpretação possível para a baixa participação na primeira rodada em relação às demais é a falta de conhecimento das regras no início do marco regulatório e ao progressivo amadurecimento institucional do novo mecanismo de designação de blocos.

Tabela 1: Participação de empresas nas rodadas de licitação

\begin{tabular}{llllllllllll}
\hline Round & $1^{o}$ & $2^{o}$ & $3^{o}$ & $4^{o}$ & $5^{o}$ & $6^{o}$ & $7^{o}$ & $8^{o}$ & $9^{o}$ & $10^{o}$ & Total \\
\hline Empresas interessadas & 58 & 49 & 46 & 35 & 18 & 30 & 52 & 48 & 74 & 52 & 462 \\
Empresas habilitadas & 38 & 44 & 42 & 29 & 12 & 24 & 44 & 43 & 61 & 40 & 377 \\
Empresas ofertantes & 14 & 27 & 26 & 17 & 6 & 21 & 32 & 27 & 42 & 23 & 235 \\
Empresas vencedoras & 11 & 16 & 22 & 14 & 6 & 19 & 30 & 23 & 36 & 17 & 194 \\
\hline
\end{tabular}

Fonte: Elaboração própria, com base nos dados da ANP.

Segundo Mattos (2008), o problema da assimetria de informação entre jogadores, acerca do valor do objeto leiloado, é muito grande nos leilões da ANP. Tendo em visa que a Petrobras operou sozinha neste mercado por quase 50 anos (no período anterior a quebra do seu monopólio em 1997), sendo responsável por todo o estudo geológico para prospecção de petróleo no Brasil, o autor argumenta que a estatal acumulou informações muito mais precisas sobre as áreas colocadas em leilão do que qualquer outro investidor pode obter. Dessa forma, se qualquer jogador ganhar o leilão com um lance superior ao da Petrobras, é bem provável que sua oferta esteja acima do potencial econômico do bloco arrematado. Por isso, o autor argumenta que o receio da maldição do vencedor se torna um componente forte na expectativa das demais companhias, explicando não apenas o elevado percentual de sucesso da Petrobras, como também a relativa retração dos grupos privados que participam do lei- 
lão sem associação com a estatal. ${ }^{6}$

Outro elemento que configura uma relação de assimetria na indústria brasileira de petróleo foi a chamada Rodada Zero, realizada em agosto de 1998, na qual foram concedidos à Petrobras os direitos de exploração em blocos nas quais a empresa já mantinha atividades, com o objetivo de enquadrá-la ao novo marco regulatório. Na ocasião, foram assinados 397 contratos $^{7}$ de concessão com a Agência Nacional do Petróleo, com prazos de três anos para Declaração de Comercialidade, sendo que alguns destes blocos foram devolvidos em 2000. Assim, a Petrobras tomou parte nos leilões subsequentes já desenvolvendo atividades produtivas nas proximidades dos blocos licitados, o que não ocorreu com os demais participantes.

De fato, a taxa de sucesso dos lances empreendidos pela Petrobras, sozinha ou em consórcio com outras empresas, é significativamente alta. A Figura 1 mostra a taxa de aproveitamento dos lances da Petrobras em cada uma das dez rodadas de leilões realizadas, isto é, o percentual de lances vencedores em relação aos efetuados pela empresa. Na quinta, sexta, oitava e nona rodadas, a estatal ganhou quase cem por cento dos leilões de que participou, sendo que apenas na nona rodada não obteve um aproveitamento acima de $70 \%$ dos seus lances.

Mattos (2008) sugere que a assimetria que permite um desempenho tão favorável da Petrobrás tem caráter informacional, mas outras duas hipóteses podem ser levantadas para explicar tal desempenho. A primeira seria que a Petrobras possui melhor capacidade e tecnologia para exploração, desenvolvimento e produção de petróleo e gás natural no território brasileiro, avaliando de forma diferenciada os blocos licitados. Assim como a hipótese de assimetria informacional, essa hipótese estaria relacionada com o aprendizado adquirido pela Petrobras ao longo de décadas como monopolista do setor. A outra possibilidade a ser considerada é que, por ser uma empresa estatal, a Petrobras não considera somente critérios técnicos ao definir o valor de seus lances, mas também critérios políticos, fruto de pressões governamentais que explicam seu sucesso nos leilões da ANP. Ao ofertar lances altos, a Petrobras aumentaria a receita do governo com os bônus de assinatura - o que na prática representaria uma estratégia de repasse de recursos da estatal ao Tesouro - além de aumentar a probabilidade de manter a exploração do petróleo sob o controle indireto do governo. ${ }^{8}$ Além disso, o governo poderia estar interessado em elevar a competitividade dos leilões futuros, pressionando a Petrobras a oferecer altos lances, a fim de fornecer sinais aos potenciais investidores sobre a qualidade da prospecção de petróleo no território brasileiro. ${ }^{9}$

\footnotetext{
${ }^{6} \mathrm{~A}$ interpretação das assimetrias como provenientes de vantagens informacionais e a própria maldição do vencedor partem da hipótese de valor comum, o que é bastante razoável no caso de leilões de petróleo. Sob a hipótese de valor privado, ou mesmo correlacionado, as assimetrias podem ser atribuídas a diferenças de valoração do bloco, provenientes, por exemplo, de vantagens tecnológicas. Ao longo deste artigo, estamos interessados em documentar a eventual existência de assimetrias, e sua atribuição a eventuais vantagens informacionais está condicionada à hipótese de leilão de valor comum.

${ }^{7}$ Fonte: ANP, Rodada Zero.

${ }^{8}$ Durante décadas, a Petrobras foi o agente pelo qual o governo brasileiro operacionalizou sua estratégia de cunho nacionalista com vistas a se apropriar integralmente dos benefícios econômicos das atividades da Indústria do Petróleo.

${ }^{9}$ É reconhecida a existência de evidências de interferência política na gestão dos negócios da Petrobras. A própria disparidade entre a tendência do preço mundial do petróleo nos últimos anos e o preço de seus derivados no mercado nacional sugere isso.
} 
Nesse sentido, uma análise mais apurada da nona rodada de licitações, realizada em novembro de 2007 , pode ser importante na avaliação de tais hipóteses. Nesta rodada, a mesma em que a Petrobras obteve seu pior desempenho (Figura 1), outra competidora surgiu com elevado aproveitamento. A OGX, empresa constituída em julho de 2007 (apenas quatro meses antes da licitação) com um capital inicial de US $\$ 1,285$ bilhões, ${ }^{10}$ quebrou a hegemonia da Petrobras ao participar de 23 leilões de blocos de áreas para exploração, sagrando-se vencedora em 21 deles, sendo responsável por $70 \%$ da receita de Bônus de Assinatura obtida pelo governo com a nona rodada. A OGX não ofertou nenhum lance na décima rodada. A Figura também apresenta o aproveitamento dos lances da Petrobras (barras claras) e da OGX (barra escura) nas dez rodadas.

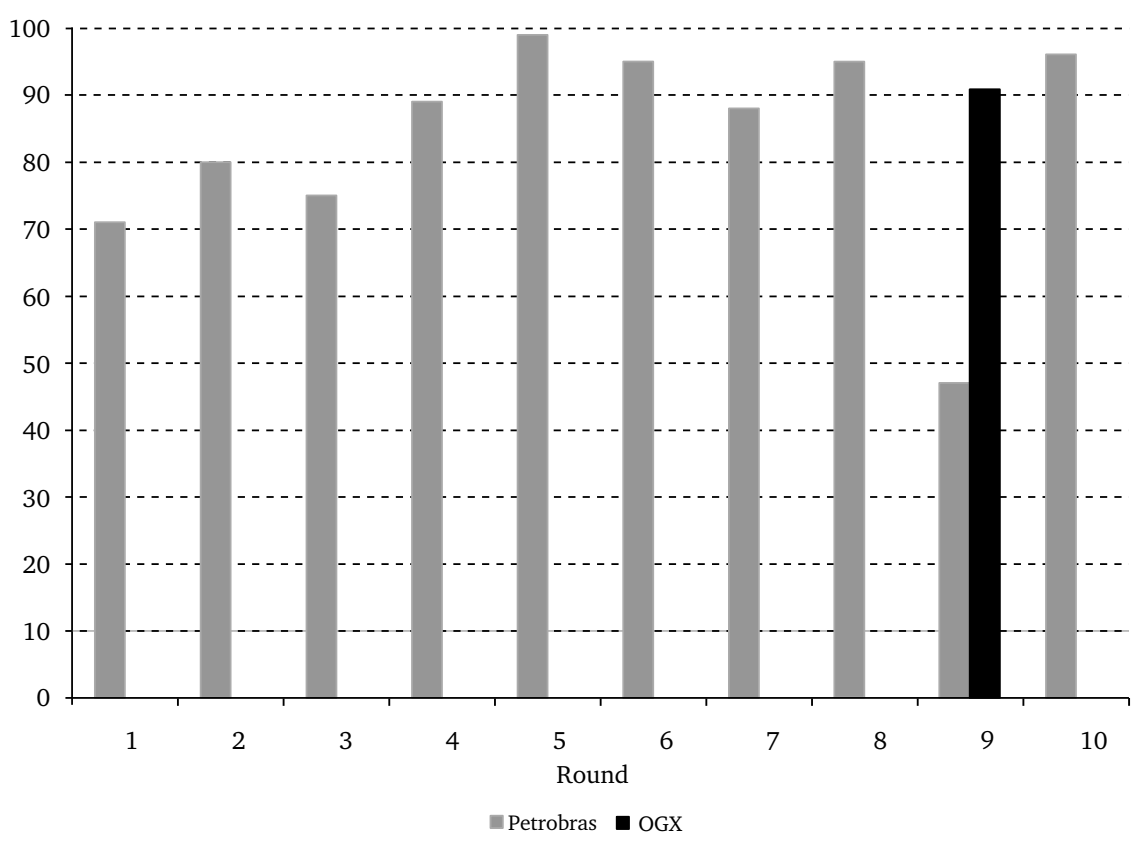

Figura 1: Taxas de aproveitamento dos lances da Petrobras e da OGX, em \%.

O aproveitamento da Petrobras na nona rodada foi de apenas $47 \%$, enquanto a OGX conquistou 91\%. Em 14 de seus 23 lances, a OGX não participou de consórcio e venceu todos. A Petrobras disputou diretamente contra a OGX sete blocos e não venceu nenhum, sendo que seis foram vencidos pela OGX e um por outro concorrente. ${ }^{11}$ A taxa de sucesso total da Petrobras após o término da nona rodada caiu para $86 \%$, ante os $92 \%$ conquistados até a rodada anterior. Além disso, vale destacar que a OGX foi aceita nos leilões desta rodada como operadora do tipo B, ou seja, em uma categoria de empresas que só podem explorar áreas em terra firme ou em águas rasas, limitando sua atuação, dado que os blocos mais produtivos estão em águas profundas.

A OGX pertence a um grupo de empresas que atua nos ramos de extração de minério de ferro, transportes, siderurgia e geração de energia. Sua estratégia para entrar na Indústria do Petróleo foi pautada por uma busca agres-

\footnotetext{
${ }^{10}$ Disponível em http://www.ogx.com.br. Acesso em 15/07/2009.

${ }^{11} \mathrm{O}$ bloco ES-M-470 foi vencido pela empresa Ongc Videsh.
} 
siva de profissionais com larga experiência no setor e know-how na gestão de atividades ligadas a exploração e produção de gás natural e petróleo no Brasil. No mercado, é reconhecida a transferência de capital humano altamente qualificado da estatal para a OGX, que contou com a contratação de aproximadamente 30 executivos atraídos por altos salários e bônus por performance. Entre os profissionais que atuam na OGX destacam-se engenheiros, geólogos e altos executivos provenientes dos quadros da Petrobras e também de outras estatais, além do BNDES e do Banco Central. ${ }^{12}$

Essa expressiva atração de quadros da Petrobras permite supor que a OGX absorveu também boa parte da informação e do capital humano da estatal. Por outro lado, a alta taxa de aproveitamento da OGX na nona rodada é um indício contrário à hipótese de que o aproveitamento da Petrobras nas licitações anteriores seja resultado de incentivos decorrentes de influências políticas.

Embora a análise não seja conclusiva nesse estágio, as características apresentadas acima são consistentes com a hipótese de transferência de vantagem informacional da estatal para a OGX, pois, de fato, esta última absorveu apenas quadros profissionais, e não capital físico da Petrobras, o que corrobora a hipótese da presença de assimetria informacional.

\section{Resultados estilizados indicativos de assimetrias}

O objetivo desta seção é listar resultados de um modelo de leilão com competidores assimétricos, a fim de evidenciar alguns fatos estilizados desse tipo de certame. Assumindo a hipótese de que a Petrobras possuía informações privadas sobre os blocos leiloados - o que lhe conferiria vantagens sobre os demais concorrentes ao impor a estes que a vitória num leilão traria um elevado risco de incorrer na maldição do vencedor - algumas questões sobre a expressiva presença de outros concorrentes em todas as rodadas emergem naturalmente: por que investidores sem informações privadas participam de um leilão mesmo quando existe um competidor com tais informações? Além disso, o que explica o oferecimento de lances maiores por firmas sem informações privadas, mesmo quando um competidor com tais informações apresenta ofertas?

Deve-se a Engelbrecht-Wiggans et al. (1983) uma das principais contribuições no estudo de leilões com assimetria de informações entre os participantes. Seu principal resultado é o de que o agente informado apresenta esperança de lucro positiva, ao passo que, para o agente não informado, este valor é zero. Porter (1995) e Hendricks et al. (1994) respondem a esses questionamentos com um modelo que estuda as estratégias de equilíbrio em leilões para exploração de jazidas de valor comum com a presença de assimetria de informação. Algumas conclusões gerais destes modelos são:

a) Na presença de assimetria decorrente de vantagens informacionais, os competidores informados apresentam tendência a uma maior taxa de

\footnotetext{
${ }^{12}$ Ver http://portalexame.abril.com.br/servicos/guiadoinvestidor/ artigos/m0161973.html http://epocanegocios.globo.com/Revista/ Epocanegocios/0, ,EDG83434-8374-15-5,00-o+enigma+eike.html http:// wWw.estadao.com.br/estadaodehoje/20071128/not_imp86829,0.php http:// ultimosegundo.ig.com.br/economia/2007/09/05/eike_vai_criar_a_ petroleira_ogx_991936.html.Acesso em 14/07/2008.
} 
aproveitamento, isto é, possuem maior probabilidade de ganhar o leilão, condicionada ao oferecimento do lance;

b) As distribuições dos lances dos concorrentes informados e dos lances máximos dos não informados coincidem para valores acima do preço de reserva (Engelbrecht-Wiggans et al. 1983, Hendricks et al. 1994)

c) Os concorrentes não informados têm lucro esperado nulo e incorrem em maldição do vencedor nas áreas leiloadas em que o competidor informado não oferece lances, mas possui ganho esperado positivo quando vence um competidor informado, já que este subestima o lance em relação a seu preço de reserva;

d) O concorrente informado possui renda de informação positiva, isto é, seu lance de equilíbrio é menor que seu valor de reserva.

As predições teóricas descritas acima indicam algumas razões pelas quais não haveria incompatibilidade entre a presença de assimetria de informação em favor da Petrobras ${ }^{13}$ e a participação de outros concorrentes nos leilões da ANP. Mas mesmo essas predições associadas ao expressivo aproveitamento da Petrobras não permitem afirmar que as licitações para exploração de gás e petróleo no Brasil estão permeadas por assimetrias entre os concorrentes. Por conta disso, as seções seguintes buscam aprofundar a análise dessa hipótese através de um estudo exploratório do banco de dados gerado pelas dez rodadas de leilões realizadas até aqui.

\section{Banco de dados}

O banco de dados utilizado neste estudo foi construído a partir de informações da Agência Nacional do Petróleo (ANP) referentes às dez rodadas de leilões realizadas entre 1999 e 2008. Para cada bloco leiloado, os dados contemplam informações sobre sua área, a bacia e o setor a que pertence, a rodada em que foi leiloado, localização (mar ou terra), o número de lances ofertados, as empresas que ofereceram os lances, as empresas que deram lance em consórcios e suas respectivas participações, as empresas operadoras e os lances oferecidos.

Os critérios para definição do vencedor de cada leilão variaram um pouco ao longo das rodadas. De maneira geral, além do bônus de assinatura, compromissos assumidos pelos licitantes para utilização de fornecedores e mão de obra nacionais e o plano de investimento proposto são levados em consideração. Dessa forma, cada lance ofertado contempla algumas informações que geram uma pontuação de 0 até 100 para a oferta, consagrando-se como lance vencedor aquele que obtiver o maior valor.

Tendo em vista que o objetivo deste trabalho é avaliar a presença de assimetrias entre os concorrentes, que o bônus de assinatura possui um peso de $85 \%$ na definição dessa pontuação e que os demais critérios são relativamente homogêneos entre os lances ofertados em um mesmo leilão, a análise aqui realizada é focada nos bônus de assinatura oferecidos. ${ }^{14}$

\footnotetext{
${ }^{13} \mathrm{E}$, a partir da $9^{a}$ rodada, em favor da OGX.

${ }^{14}$ De fato, menos de $5 \%$ dos blocos arrematados tiveram um lance vencedor com bônus de assinatura que não foi o maior oferecido. Além disso, o Programa Exploratório Mínimo (PEM)
} 
Nessas dez rodadas, foram arrematados 803 blocos que receberam 1.282 lances. Dos blocos arrematados, 311 localizam-se no mar e receberam 396 lances, consequentemente, 192 localizam-se na terra e receberam 886 lances.

Em linha com o apresentado na Figura 1, a empresa com maior sucesso nos leilões foi a Petrobras que participou de $58 \%$ dos leilões, oferecendo 464 lances e ganhando 402 vezes (representando uma taxa de aproveitamento de $87 \%$, sempre acima da média global). ${ }^{15}$ A exceção a este sucesso da Petrobras ocorreu na nona rodada, quando ela obteve apenas $47 \%$ de aproveitamento dos seus lances. Nesse mesmo round, a OGX conquistou um aproveitamento de $91 \%$, oferecendo 23 lances sendo que 21 consagraram-se vencedores (sozinhos ou em consórcios).

Cerca de um terço dos lances foi dado em consórcio, mas esta não parece ser uma estratégia comum dos vencedores, pois o aproveitamento total dos lances em consórcio é de apenas 63\%. Nas rodadas 4, 5 e 6 este aproveitamento foi significativo (respectivamente, 100\%, 100\% e $81 \%$ ), mas é importante destacar que nessas rodadas - além de haver poucos lances em consórcio - houve participação da Petrobras em exatamente 100\%, 100\% e $81 \%$ dos lances em consórcio vencedores, respectivamente. Isso reforça os indícios de que oferecer lances junto com a Petrobras é uma estratégia mais eficiente do que simplesmente oferecer lances em consórcio.

A Tabela 2 exibe o sumário das dez rodadas de licitação com as informações que foram destacadas até aqui.

\section{Estudo estatístico dos lances}

Com o objetivo de investigar evidências mais robustas da presença e do padrão de assimetrias entre os participantes, a Tabela 3 apresenta o resumo estatístico dos lances empreendidos nas dez rodadas. As ofertas foram calculadas através do valor médio real do bônus por área, obtido pela média dos bônus de assinatura com valores constantes de 1999 por $\mathrm{km}^{2}$ do bloco em licitação. Dos 1.282 lances oferecidos nas dez rodadas, foram retirados da amostra 528 lances oferecidos em leilões de blocos que receberam somente um lance. Essa exclusão teve o objetivo de impedir que blocos com baixa procura, e, consequentemente, com maior probabilidade de que os vencedores tenham dado lances subestimados, ${ }^{16}$ pudessem enviesar os valores médios dos lances que se supõe refletirem a estimação técnica do mercado para o valor do bloco licitado.

A primeira característica revelada é que os lances da Petrobras e da OGX (por unidade de área) foram em média bastante superiores aos lances dos demais participantes. Outro aspecto importante é que os lances ofertados pela

foi instituído como critério de pontuação a partir de 2003. O PEM médio oferecido pela Petrobras em seus lances vencedores (1085) é levemente acima da média dos lances vencedores das demais (1031), sendo que esta diferença não é estatisticamente significativa a $10 \%$, pelo teste de igualdade de médias com variâncias desiguais. O mesmo vale para o compromisso com conteúdo nacional na fase de exploração (65,9\% da Petrobras contra $66 \%$ das demais vencedoras) e na fase de desenvolvimento $(73,2 \%$ versus $73 \%)$. Fonte: Cálculos próprios, com base no banco de dados.

${ }^{15}$ Inclui situações em que a estatal estava sozinha ou participando de um consórcio. Para os dois casos, considera-se que ela utilizou todo seu conjunto de informações para otimizar o lance.

${ }^{16}$ A racionalidade deste comportamento é explicada em Porter (1995). Entre outros, isso pode ocorrer porque a empresa ou consórcio que fez o único lance poderia já ter alguma indicação de que o Bloco não seria atrativo para os outros participantes do leilão e, portanto, aumentaria sua disposição para dar um lance abaixo do que ela acreditaria valer o bloco. 


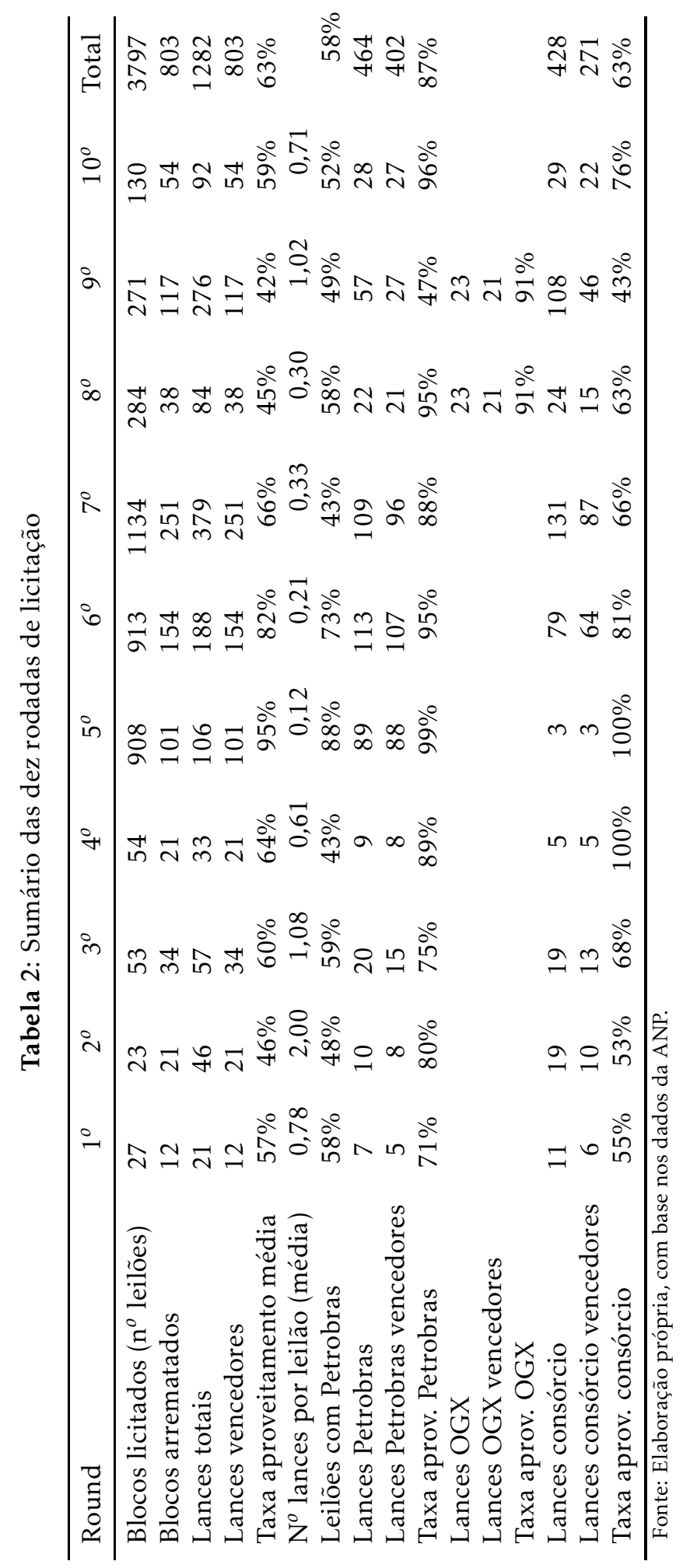




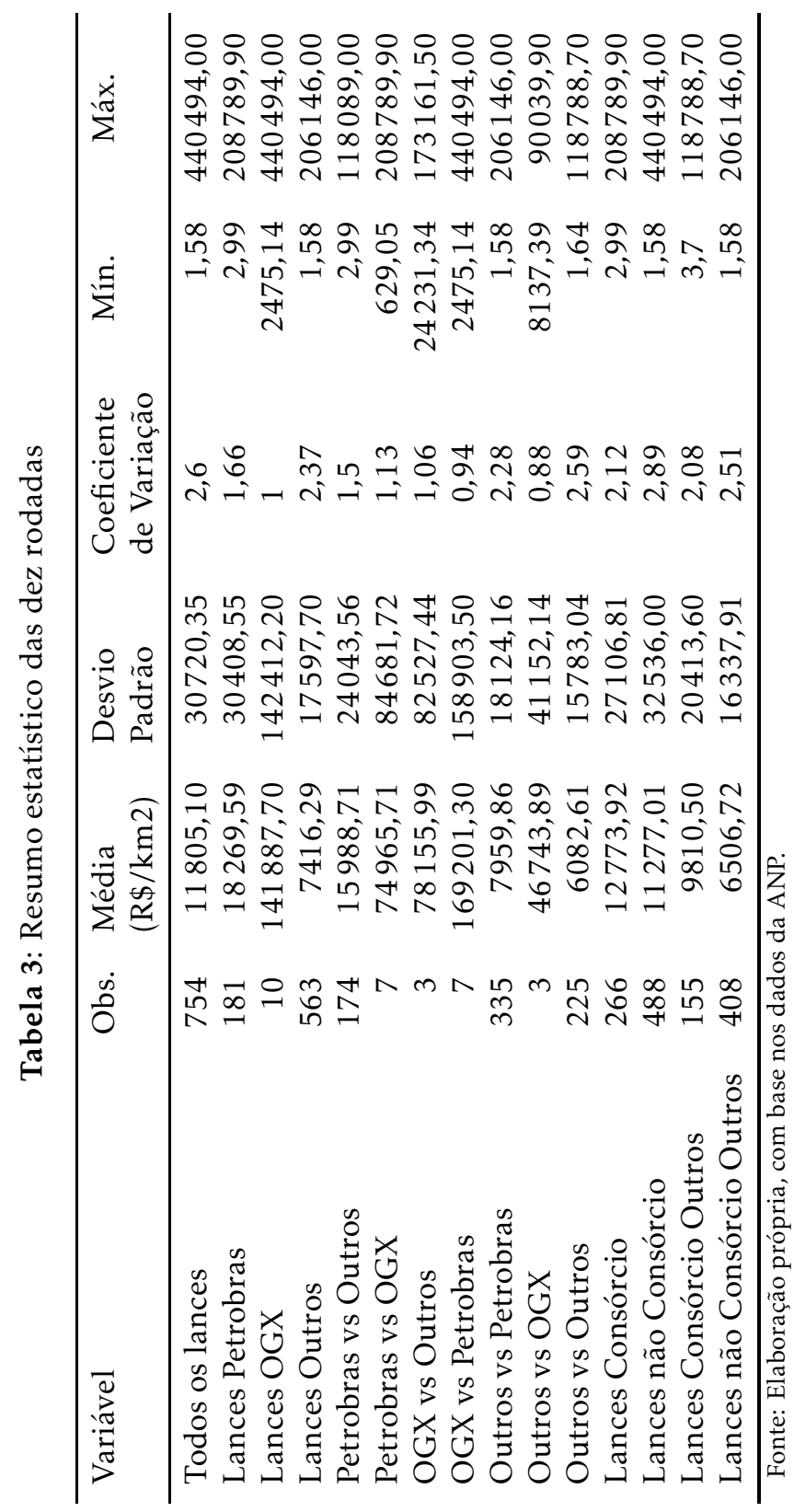


Petrobras contra a OGX (Petrobras vs OGX) e os lances ofertados pela OGX contra a Petrobras (OGX vs Petrobras) foram também em média superiores aos seus respectivos lances contra outras empresas (Petrobras vs Outros e OGX vs Outros). Esse padrão se mantém nos lances das outras empresas contra Petrobras e OGX, superiores aos lances ofertados nos leilões em que elas não participaram (Outros vs Outros). Isso sugere que a estratégia de cada participante se relaciona com quem será seu oponente, o que, conforme especulado por Campo et al. (2003), pode estar associado à presença de assimetria de informações entre os participantes. Por fim, o último bloco da tabela mostra que lances em consórcio são ligeiramente superiores a lances ofertados por empresas sozinhas. Essa diferença fica um pouco maior quando separamos os lances em consórcio ou não, mas tirando os lances com participação da Petrobras e da OGX (Lances Consórcio Outros e Lances não Consórcio Outros).

A Tabela 4 exibe a estatística $t$ para os testes de média em que a hipótese nula é que a média do grupo da primeira linha menos a média do grupo da segunda é igual a zero. O teste para os lances em consórcio ou não incluindo Petrobras e OGX não rejeitou a hipótese nula, enquanto a exclusão dessas duas empresas levou à rejeição com 5\% de significância. O teste para os lances da OGX contra a Petrobras e contra as demais empresas também não rejeitou a hipótese nula, provavelmente, por conta do baixíssimo número de observações. Por fim, o teste para os lances de outras empresas contra Petrobras ou contra outras empresas também não rejeitou a hipótese nula. Em todos os demais casos os testes apontaram para uma diferença entre as médias de acordo com o exposto na Tabela 3.

A grande variabilidade dos lances, atestada pelos altos níveis de desvio padrão encontrados na Tabela 3, além da grande escala de valores para os lances, podem estar relacionadas parcialmente com a heterogeneidade dos blocos. Nesse sentido, as tabelas a seguir separam os lances de acordo com blocos localizados no mar e na terra. Embora fique claro que os blocos no mar recebam lances maiores que os blocos na terra, os principais resultados encontrados na Tabela 3 não se alteram significativamente.

O resumo estatístico para os blocos localizados no mar (Tabela 5) mostra que os lances da Petrobras e da OGX foram em média bastante superiores aos lances das demais empresas. Quanto aos lances da Petrobras contra a OGX e da OGX contra a Petrobras estes também foram em média superiores aos lances destas empresas contra as demais participantes. O mesmo padrão encontrado na Tabela 3 também se mantém para os lances das outras empresas, ou seja, elas ofertaram lances em média superiores quando concorreram com a Petrobras e a OGX. Já quanto aos lances em consórcio, desta vez eles aparecem em média inferiores aos lances individuais, mas essa relação se inverte quando se retiram os lances da Petrobras e da OGX, indicando mais uma vez que a influência destas é mais significativa para o padrão do lance oferecido do que o consórcio em si.

A Tabela 6 exibe a estatística $t$ para os testes de média dos lances ofertados em blocos localizados no mar. A hipótese nula é que a média do primeiro elemento (primeira linha) menos a média do segundo (segunda linha) é igual a zero. Os testes apresentam um padrão muito semelhante ao padrão encontrado na Tabela 4, mas desta vez os lances das outras empresas contra a Petrobras se mostraram estatisticamente superiores aos lances das outras empresas contra outras empresas.

Quanto aos blocos localizados na terra (Tabela 7) — que não receberam 


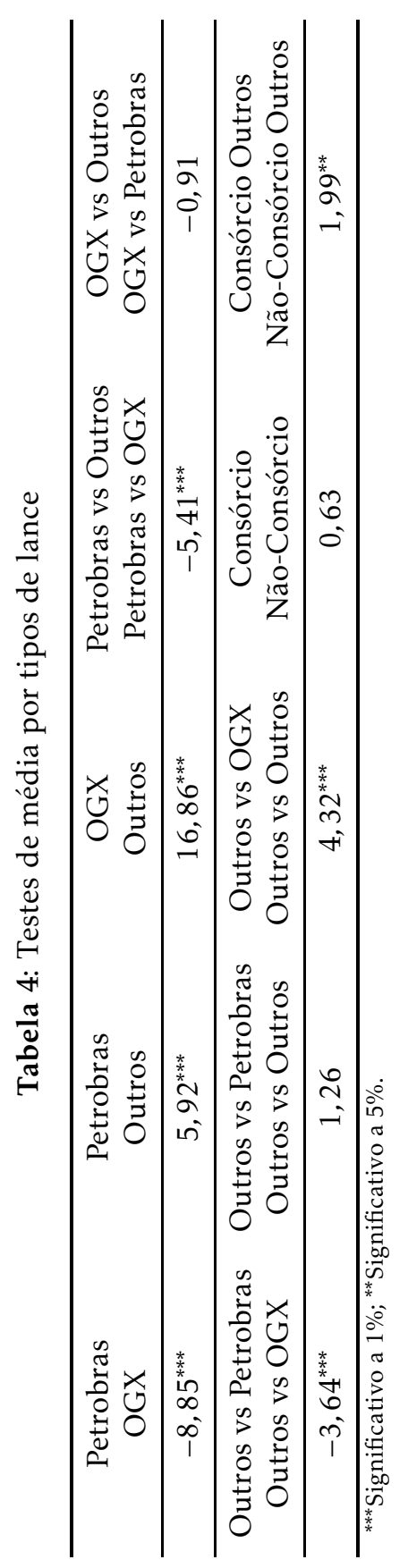




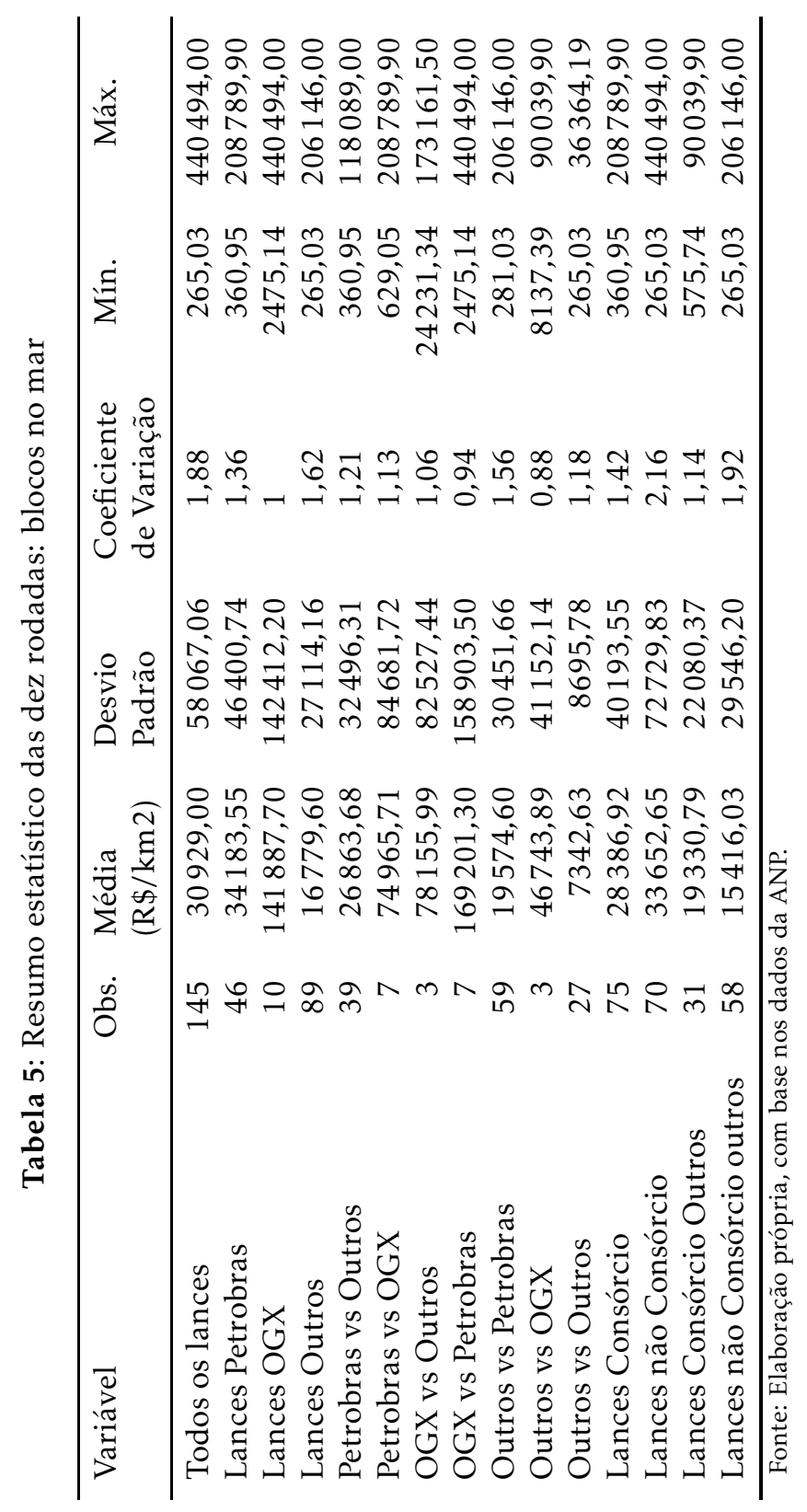




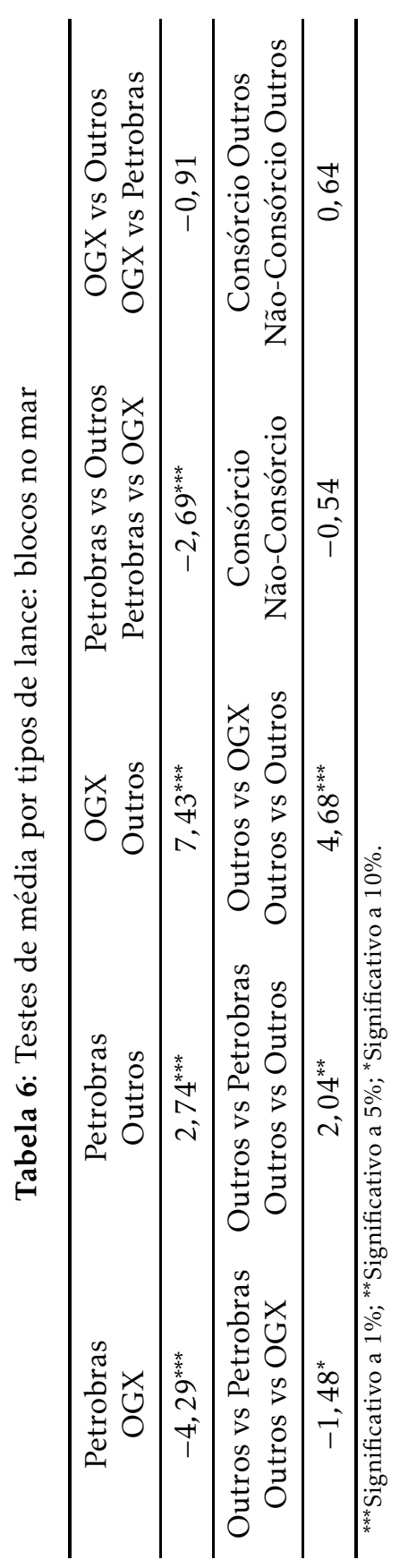


lances da OGX -, mais uma vez os lances da Petrobras foram em média bastante superiores aos lances das demais empresas. Por outro lado, desta vez, os lances de Outros vs Petrobras se mostraram ligeiramente inferiores aos lances de Outros vs Outros, apesar de o teste de média não indicar diferença estatística entre eles (Tabela 8). Já os lances em consórcio apresentaram o mesmo padrão encontrado na Tabela 5.

A Tabela 8 exibe a estatística $t$ para os testes de média dos lances ofertados em blocos localizados na terra. Mais uma vez, a hipótese nula é que a média do primeiro elemento menos a média do segundo é igual a zero. Os lances da Petrobras se mostraram significativamente superiores aos lances das demais empresas, assim como os lances em consórcio quando eliminamos a participação da Petrobras.

Os resultados apresentados nesta seção reforçam os indícios de assimetria entre os participantes e deixam claro que o padrão desta assimetria está ligado à presença da Petrobras e da OGX, ao contrário do encontrado por Campo et al. (2003), em que a assimetria era identificada com a presença de consórcios. Dessa forma, é natural esperar que a distribuição de probabilidades dos lances da Petrobras e da OGX seja diferente da distribuição dos demais competidores. Com o intuito de testarmos esta possibilidade, a seção seguinte estima não parametricamente tais distribuições e testa a diferença entre elas. ${ }^{17}$

\section{Diferença na distribuição dos lances}

A partir da década de 1990, a literatura sobre leilões ganhou novo impulso com a crescente utilização de modelos estruturais ${ }^{18}$ para a análise de dados de leilões. Tais modelos partem da hipótese de que os lances observados são resultantes das estratégias de equilíbrio do jogo em andamento. Contribuições importantes nesta área são oferecidas por Bajari \& Hortacsu (2005), Campo et al. (2003), Perrigne \& Vuong (1999) e Guerre et al. (2000). A estimação da densidade e da distribuição acumulada dos lances implementada neste trabalho segue a metodologia consagrada por estes autores, através de uma estimação não paramétrica via estimador Kernel (Li \& Racine 2007). Com esta metodologia, a densidade estimada em qualquer ponto $x$ será:

$$
f(x)=\frac{1}{m} \sum_{i=1}^{m} K\left(\frac{x-x(i)}{h}\right)
$$

onde $m$ é o número de observações (no caso em tela, o número de leilões), $K$ é a função Kernel tal que $\int K(t) d t=1$ e $h$ é a janela de estimação escolhida (bandwidth).

A escolha da função Kernel não traz muitos efeitos práticos para a estimação (Li \& Racine 2007, cap. 01). De qualquer forma, optou-se pela função Kernel triweight dado que esta é simétrica e duas vezes continuamente di-

\footnotetext{
${ }^{17}$ Importa observar que esse teste não pretende investigar o resultado (b) mencionado na seção 4, segundo o qual os lances dos informados e os lances máximos dos não informados coincidem, na presença de custos simétricos. Ainda que a hipótese nula de igualdade de distribuição não fosse rejeitada, não seria possível concluir a presença de assimetrias informacionais, pois tal resultado poderia indicar a presença de competidores homogêneos em informação e custos.

${ }^{18}$ Para um survey de métodos para leilões fechados de primeiro preço, ver Perrigne e Vuong (1999).
} 


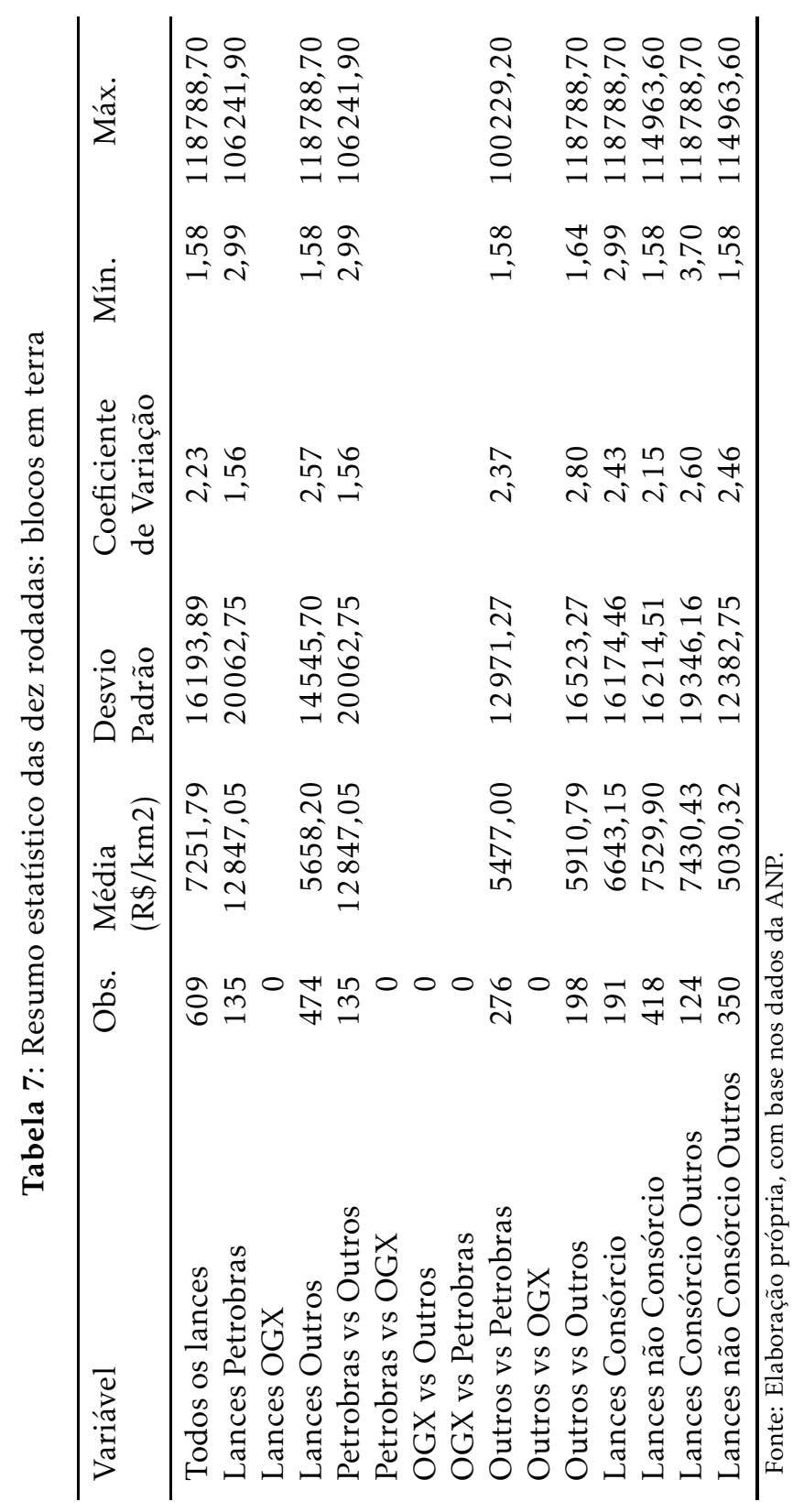




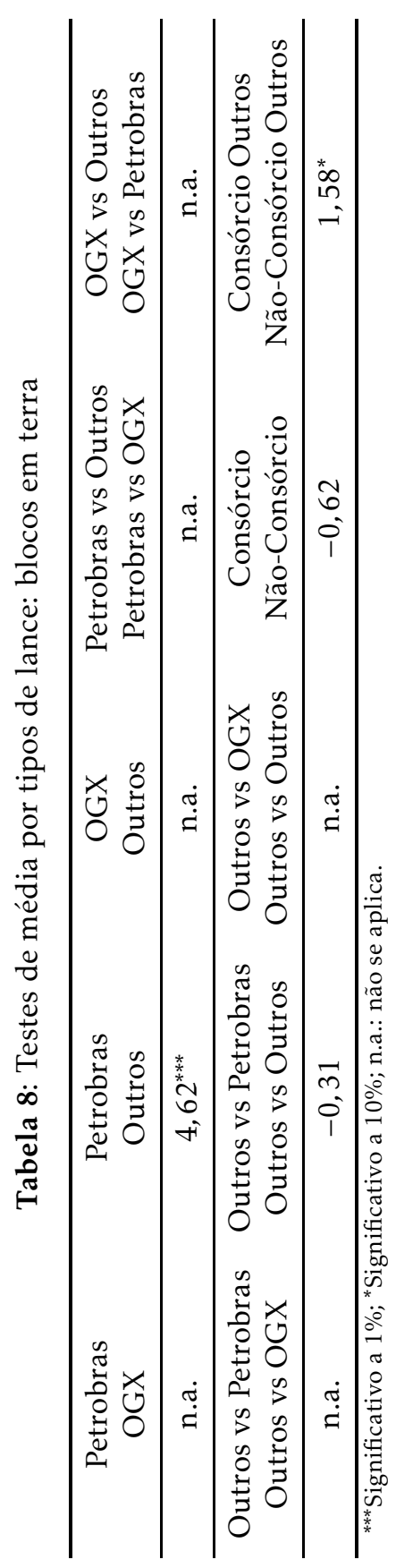


ferenciável em seus argumentos, conforme demonstram Guerre et al. (2000). Esta função é dada por:

$$
K(u)=\frac{35}{32}\left(1-u^{2}\right)^{3} I(|u| \leq 1)
$$

onde $u$ é o argumento da função e $I(|u| \leq 1)$ é uma função indicadora.

Diferentemente do tipo de função Kernel, a definição da janela de estimação $(h)$ requer maior atenção devido à sensibilidade dos resultados a essa escolha. Esse parâmetro é uma sequência de constantes que converge para zero conforme o número de observações tende ao infinito, estabelecendo a extensão da vizinhança em torno de um ponto ao redor do qual o Kernel utilizará observações para efetuar a estimação. Portanto, a janela determina a variabilidade e o viés das estimativas, regulando a "suavidade" da distribuição de probabilidade estimada. Se o $h$ escolhido for pequeno, a estimativa terá um viés reduzido, mas uma variância elevada. Por outro lado, se o $h$ escolhido for grande, a estimativa terá um viés elevado, mas se reduzirá a variância do estimador não paramétrico $\widehat{f}($.). Ou seja, quando $h$ aproxima-se de zero, a estimativa tende a interpolar as observações, e quando $h$ aumenta, a curva estimada se aproxima de uma regressão linear (Marquetti \& Viali 2004, Paarsch et al. 2006, cap. 4).

Seguindo os argumentos de Li \& Racine (2007) e Guerre et al. (2000), utilizamos uma janela ótima dada por:

$$
h=1,06 \widehat{\sigma}_{\ell}(n L)^{-\frac{1}{5}}
$$

onde $\widehat{\sigma}_{\ell}$ é o desvio-padrão estimado dos lances, $n$ é o número de participantes por leilão e $L$ é o número de leilões na amostra - ou seja, $n L$ é o número de observações. Vale ressaltar que esta é a janela utilizada em Li et al. (2002) e Campo et al. (2003), baseada em uma "regra de bolso" desenvolvida por Silverman (1986). Tal janela minimiza o erro quadrático médio integrado, composto pela soma de dois componentes: um relativo ao viés e outro referente à variância (Li \& Racine 2007, cap. 01).

A implementação desse estimador exige a partição da base de dados em conjuntos que contemplem os leilões com o mesmo número de participantes (n), dado que se supõe que o lance ofertado por um competidor se dá em função também do número de concorrentes que ele enfrentará. Além disso, como nosso objetivo é analisar diferenças nas distribuições dos lances da Petrobras e da OGX em relação às demais participantes, separamos as observações em dois grupos formados conforme o padrão de assimetria a ser testado. A Tabela 9 resume as observações de acordo com o número de participantes por leilão.

A estimação das densidades e das distribuições acumuladas foi possível apenas para os leilões com dois ou três participantes. Isso porque, seguindo a mesma metodologia adotada anteriormente, os leilões com um participante foram descartados com o objetivo de evitar que blocos com baixa procura e com maior probabilidade de que os vencedores tenham dado lances subestimados - pudessem enviesar as estimações que se supõem refletirem a estimação técnica do mercado para o valor do bloco licitado. Já os leilões com mais de três participantes foram descartados por conta do baixo número de observações, o que enfraqueceria significativamente a robustez dos resultados encontrados. ${ }^{19}$

\footnotetext{
${ }^{19}$ Foi implementado também um aparamento nas caudas das distribuições estimadas com o
} 
Tabela 9: Observações por número de participantes no leilão $n$

\begin{tabular}{|c|c|c|c|c|}
\hline$n$ & Leilões & Lances & Petrobras e OGX & Outros \\
\hline 1 & 528 & 528 & 296 & 232 \\
\hline 2 & 164 & 328 & 104 & 224 \\
\hline 3 & 60 & 180 & 47 & 133 \\
\hline 4 & 26 & 104 & 18 & 86 \\
\hline 5 & 14 & 70 & 12 & 58 \\
\hline 6 & 7 & 42 & 6 & 36 \\
\hline 7 & 2 & 14 & 2 & 12 \\
\hline \multirow[t]{2}{*}{8} & 2 & 16 & 2 & 14 \\
\hline & 803 & 1282 & 487 & 795 \\
\hline
\end{tabular}

Fonte: Elaboração própria, com base nos dados da ANP.

A Figura 2 exibe as distribuições de probabilidade estimadas do logaritmo natural dos lances da Petrobras e da OGX e dos lances das demais participantes, nos leilões com dois concorrentes. A Figura 3 traz a mesma informação para os leilões com três concorrentes. Como se pode observar, há fortes indícios visuais de que as distribuições dos dois grupos são diferentes entre si, sugerindo assimetrias entre eles. As Figuras 4 e 5 mostram as distribuições acumuladas dos lances, o que permite identificar a dominância estocástica de primeira ordem dos lances da Petrobras + OGX.

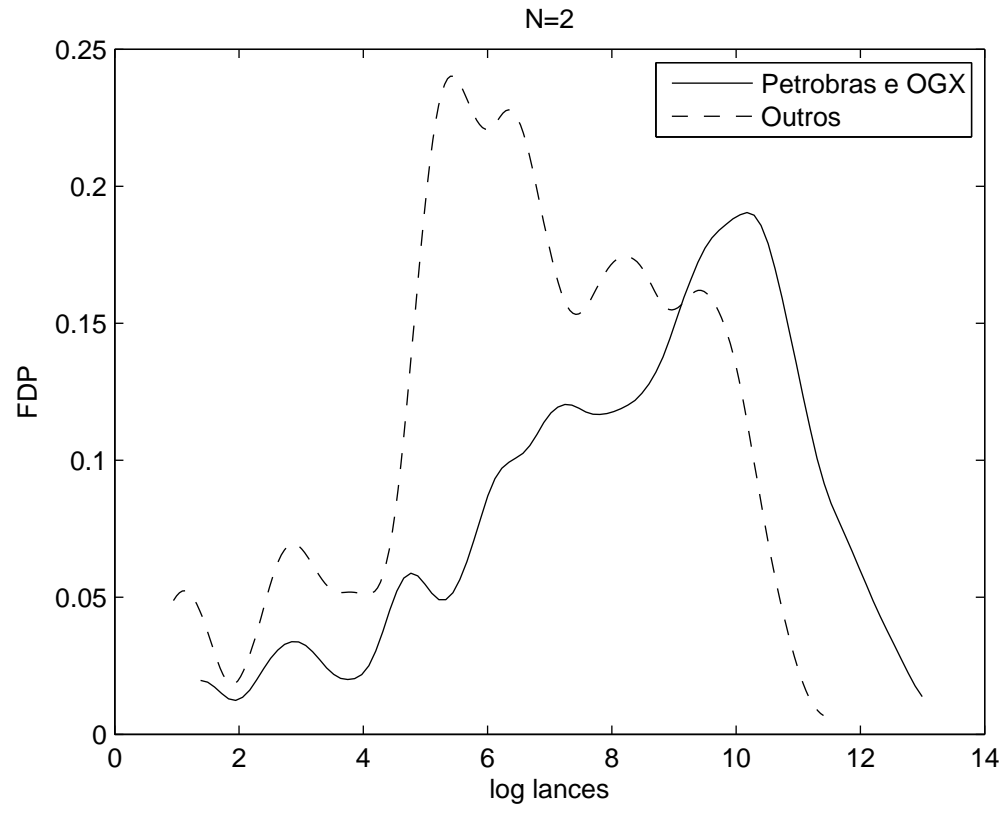

Figura 2: Densidade dos lances em leilões com dois competidores

intuito de eliminar o viés associado às observações localizadas nos extremos da amostra de lances, nos moldes do processo adotado por Campo et al. (2003). 


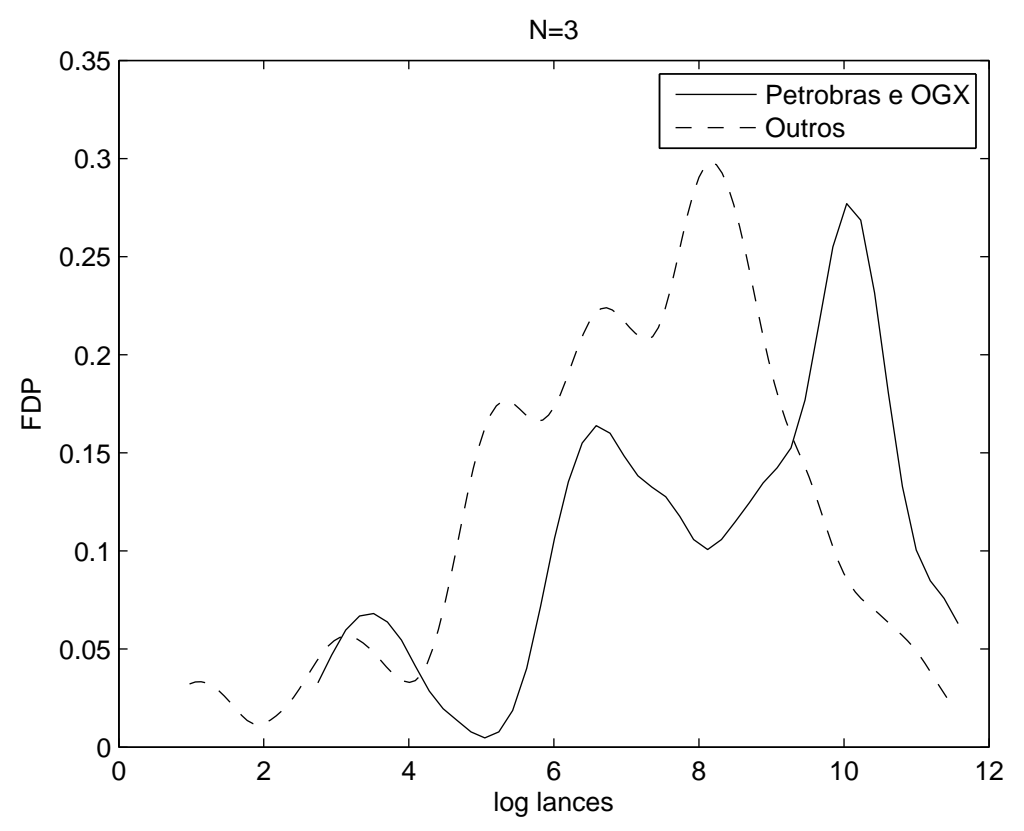

Figura 3: Densidade dos lances em leilões com três competidores

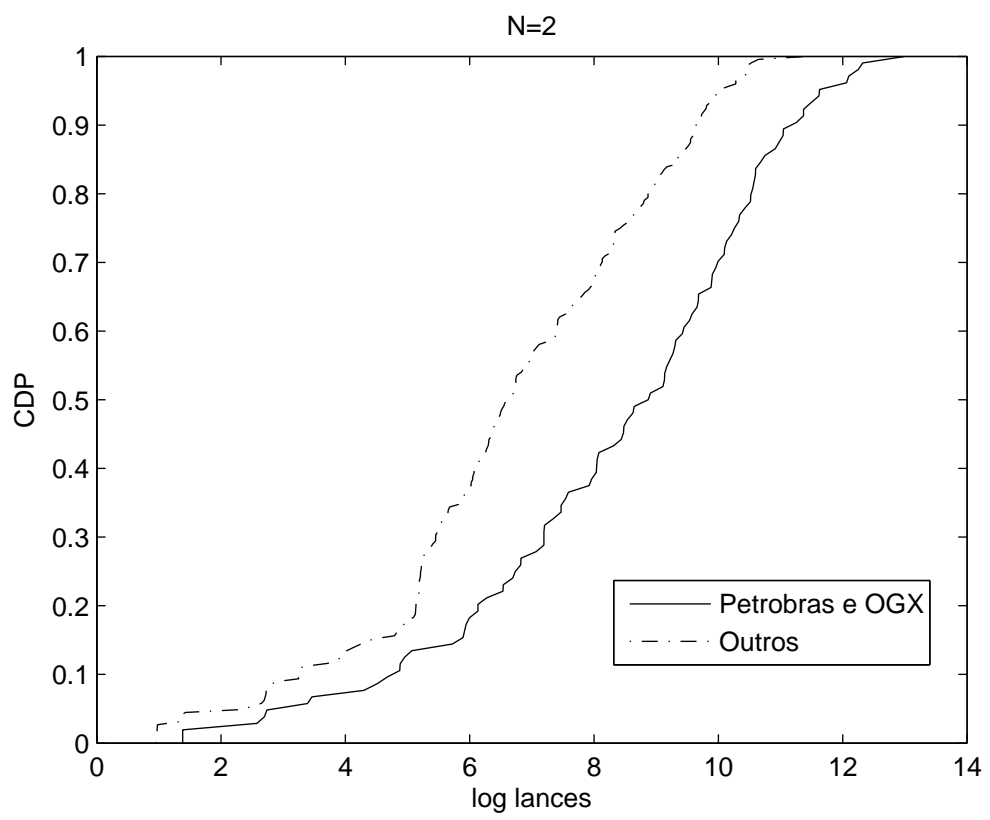

Figura 4: Distribuição acumulada dos lances, para dois competidores 


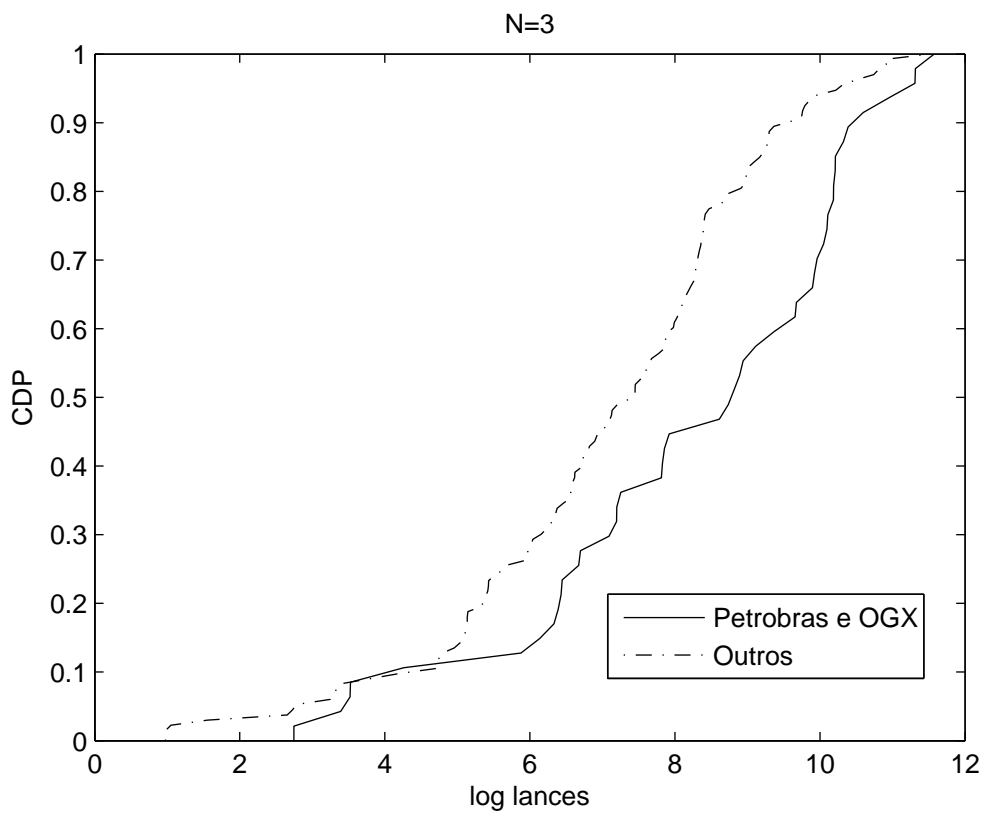

Figura 5: Distribuição acumulada dos lances, com três competidores

A fim de se avaliar se as distribuições são iguais, utilizamos o teste do Kolmogorov-Smirnov, cuja hipótese nula é a igualdade das distribuições. ${ }^{20}$ Sua ideia geral é testar se duas amostras provêm da mesma população, ou de populações diferentes com distribuições iguais, a partir da significância da diferença entre duas amostras de dados, no que se refere às suas distribuições de probabilidade cumulativas. Uma grande diferença entre os valores das duas distribuições acumuladas indica que a probabilidade dos dados terem sido gerados pela mesma distribuição é muito pequena.

A estatística $K S$ do teste é construída como:

$$
K S=\max _{x}\left\{F_{1}(x)-F_{2}(x)\right\}
$$

onde $F_{1}(x)$ e $F_{2}(x)$ são as funções de distribuição acumuladas estimadas empiricamente. A distribuição da estatística $K S$ é conhecida e independe das funções de probabilidade que se deseja testar.

A Tabela 10 apresenta os resultados do teste. Tanto nos leilões com dois quanto com três participantes, a hipótese nula foi rejeitada com $1 \%$ de significância. Esses resultados reforçam os indícios de existência de assimetrias entre os competidores dos leilões da ANP em favor da Petrobras e da OGX. A natureza destas assimetrias é indeterminada, pois, como as distribuições dos lances é desigual, não há evidências que corroborem a hipótese de assimetria informacional de Porter, embora não se possa rejeitá-la também. As assimetrias registradas também podem ser associadas a vantagens de custos.

\footnotetext{
${ }^{20}$ Para um melhor detalhamento do teste veja Lilliefors (1967).
} 
Tabela 10: Estatísticas do teste Kolmogorov-Smirnov

\begin{tabular}{lcc}
\hline $\mathrm{N}^{o}$ bidders & Estatística KS & P-Valor \\
\hline$n=2$ & $0,32074^{* * *}$ & $5,66 \mathrm{E}-07$ \\
$n=3$ & $0,32763^{* * *}$ & $8,11 \mathrm{E}-04$ \\
\hline
\end{tabular}

*** Significativo a 1 .

\section{Considerações finais}

Desde 1999, a Agência Nacional do Petróleo empreendeu dez rodadas de licitação para a concessão de áreas de exploração e produção de petróleo e gás natural no Brasil. Foram arrematados 803 blocos a partir de 1.282 lances oferecidos por mais de 100 empresas. Atualmente, além da Petrobras, mais de três dezenas de empresas privadas possuem direitos de exploração em território brasileiro e na plataforma continental. Essas licitações produziram um conjunto apreciável de informações que permitem estudar diversas propriedades estilizadas previstas em modelos teóricos de leilões. Os lances ofertados constituem uma base de dados que pode revelar particularidades importantes do mercado brasileiro de prospecção de petróleo, fornecendo subsídios para avaliações mais profundas a respeito dos sucessos e fracassos do modelo de licitação adotado. Tais estudos ganham ainda maior relevância diante do atual processo de revisão do marco regulatório do setor, após descoberta as reservas do pré-sal em 2007.

O objetivo deste artigo foi oferecer um estudo acerca de tais leilões, procurando extrair algumas conclusões sobre a possível presença de assimetria entre os participantes destas licitações. Como a Petrobras - além de ser uma concorrente controlada pelo próprio governo - foi durante quase cinquenta anos monopolista do setor, surgem questionamentos a respeito de possíveis vantagens que ela teria sobre seus concorrentes. O tema se torna importante à medida que a estrutura competitiva vigente nos leilões pode minar a eficiência das licitações em alocar o bloco para o agente com melhores condições de gerir o ativo e com maior disposição a pagar por ele, o que dificulta a maximização dos ganhos sociais obtidos com o leilão pelo poder concedente.

A análise combinada da teoria e dos dados revelou características consistentes com a presença de assimetria. A Petrobras tende a arrematar uma significativa maioria dos leilões, e os lances dos demais participantes são normalmente mais elevados quando a Petrobras está presente. Adicionalmente, a entrada da empresa OGX que - após absorver uma parte importante dos quadros profissionais qualificados da Petrobras - liderou o desempenho na única rodada de leilões de que participou se revelou um experimento compatível com uma possível natureza informacional da assimetria. Embora a evidência não seja conclusiva nesse estágio, os resultados são consistentes com a hipótese de que houve transferência de vantagem informacional da estatal para a OGX. Por fim, as distribuições dos lances da Petrobras/OGX e dos demais jogadores foram estimadas e comparadas estatisticamente a partir do teste de Kolmogorov-Smirnov, cujos resultados, ao rejeitarem a igualdade das distribuições, corroboram a presença de assimetrias nos lances, mas aludem igualmente à possível vantagem produtiva da estatal brasileira. Com outras palavras: os resultados deste artigo não reforçam nem enfraquecem a hipótese 
de assimetria informacional, mas indicam a presença de uma forte assimetria, compatível com vantagens de custos.

Apesar de seus objetivos modestos e das limitações usuais dos procedimentos não paramétricos, este artigo pretendeu lançar luz sobre as discussões a respeito da forma mais eficiente de alocar direitos de exploração de petróleo e gás, sobretudo na presença de um competidor de peso, como a Petrobras. Esse tema tem importância crescente no cenário brasileiro, diante da revisão do marco regulatório para a fronteira do pré-sal. Diversas extensões são possíveis, sobretudo referentes a procedimentos paramétricos, com vistas a identificar os determinantes dos lances.

\section{Referências Bibliográficas}

Athey, S. \& Haile, P. (2002), 'Identification of standard auction models', Econometrica 70(6), 2107-2140.

Athey, S. \& Haile, P. (2006), Empirical models of auctions, Tech report, National Bureau of Economic Research.

Bajari, P. \& Hortacsu, A. (2005), 'Are structural estimates of auction models reasonable? evidence from experimental data', Journal of Political Economy 113(4), 703-741.

Campo, S., Perrigne, I. \& Vuong, Q. (2003), 'Asymmetry in first-price auctions with affiliated private values', Journal of Applied Econometrics 18(2), 179207.

Capen, E. C., Clapp, R. V. \& Campbell, W. M. (1971), 'Competitive bidding in high-risk situations', Journal of Petroleum Technology 23(6), 641-653.

Engelbrecht-Wiggans, R., Milgrom, P. R. \& Weber, R. J. (1983), 'Competitive bidding and proprietary information', Journal of Mathematical Economics 11(2), 161-169.

Guerre, E., Perrigne, I. \& Vuong, Q. (2000), 'Optimal nonparametric estimation of first-price auctions', Econometrica 68(3), 525-574.

Hendricks, K., Pinkse, J. \& Porter, R. H. (2003), 'Empirical implications of equilibrium bidding in first-price, symmetric, common value auctions', $R e$ view of Economic Studies 70(1), 115-145.

Hendricks, K., Porter, R. H. \& Wilson, C. A. (1994), 'Auctions for oil and gas leases with an informed bidder and a random reservation price', Econometrica pp. 1415-1444.

Kagel, J. H. \& Levin, D. (1986), 'The winner's curse and public information in common value auctions', The American Economic Review pp. 894-920.

Laffont, J. J. \& Vuong, Q. (1996), 'Structural analysis of auction data', The American Economic Review pp. 414-420.

Li, Q. \& Racine, J. S. (2007), Nonparametric econometrics: Theory and practice, Princeton University Press. 
Li, T., Perrigne, I. \& Vuong, Q. (2002), 'Structural estimation of the affiliated private value auction model', RAND Journal of Economics pp. 171-193.

Lilliefors, H. W. (1967), 'On the kolmogorov-smirnov test for normality with mean and variance unknown', Journal of the American Statistical Association 62(318), 399-402.

Marquetti, A. \& Viali, L. (2004), 'Princípios e aplicações de regressão local', Análise Econômica 22(42).

Mattos, C. (2008), Licitações da ANP, Petrobras e a Maldição do Vencedor, IPEA, Rio de Janeiro, chapter Marcos regulatórios no Brasil: incentivos ao investimento e a governança.

McAfee, R. P. \& McMillan, J. (1987), 'Auctions and bidding', Journal of Economic Literature 25(2), 699-738.

Milgrom, P. R. \& Weber, R. J. (1982), 'A theory of auctions and competitive bidding. econometrica', Journal of the Econometric Society pp. 1089-1122.

Myerson, R. B. (1981), 'Optimal auction design', Mathematics of operations research $6(1), 58-73$.

Ortega-Reichert, A. (1967), Models of Competitive Bidding under Uncertainty, PhD thesis, Stanford University.

Paarsch, H. J., Hong, H. \& Haley, M. R. (2006), An introduction to the structural econometrics of auction data, The MIT Press.

Perrigne, I. \& Vuong, Q. (1999), 'Structural econometrics of first-price auctions: A survey of methods', Canadian Journal of Agricultural Economics 47, 203-223.

Porter, R. H. (1995), 'The role of information in us offshore oil and gas lease auctions', Econometrica 63(1), 1-27.

Roth, A. E. \& Kagel, J. H. (1995), The Handbook of Experimental Economics, Vol. 1, Princeton University Press Princeton.

Silverman, B. W. (1986), Density estimation for statistics and data analysis, Chapman \& Hall/CRC.

Thaler, R. H. \& Tucker, S. M. (1995), 'The winner's curse: Paradoxes and anomalies of economic life', Journal of Consumer Affairs 29(1), 295-296.

Vickrey, W. (1961), 'Counterspeculation, auctions and competitive sealed tenders', The Journal of Finance 16(1), 8-37.

Wilson, R. B. (1969), 'Competitive bidding with disparate information', Management Science pp. 446-448. 